\title{
EFICIÊNCIA TÉCNICA E ECONÔMICA DA CULTURA DA SOJA SUBMETIDA À APLICAÇÃO DE FERTILIZANTES NITROGENADOS EM SEMEADURA E COBERTURA
}

\author{
Technical and economic efficiency of soybean culture submitted to nitrogen fertilizers in sowing and covering \\ Alexandre Schefer ${ }^{1}$, Katiussa Cipriani ${ }^{2 *}$, Alceu Cericato ${ }^{3}$, André Sordi, $^{4 *}$, Cristiano Reschke Lajús ${ }^{5}$ \\ 1 Acadêmico do curso de graduação em Agronomia, Bolsista do Programa de Iniciação Científica da Universidade do Oeste \\ de Santa Catarina - Unoesc, Unidade de Maravilha. E-mail: alexandre schafer@hotmail.com. \\ 2 Acadêmica do curso de graduação em Agronomia, Universidade do Oeste de Santa Catarina - Unoesc, Unidade de Maravilha. E- \\ mail: katiussa c@hotmail.com. \\ ${ }^{3}$ Professor do Curso de Agronomia, Universidade do Oeste de Santa Catarina- UNOESC E-mail: acericato@gmail.com. \\ ${ }^{4}$ Professor do Curso de Agronomia, Universidade do Oeste de Santa Catarina-UNOESC, E-mail \\ andresordi@yahoo.com.br.
}

Artigo enviado em 24/02/2016, aceito em 31/07/2016 e publicado em 20/12/2016.

\begin{abstract}
RESUMO - Nos últimos anos, no Brasil, tem sido dada uma especial atenção ao uso de adubos nitrogenados na cultura da soja. O experimento foi conduzido na Universidade do Oeste de Santa Catarina UNOESC, Maravilha SC, com o objetivo de avaliar a eficiência técnica e econômica com aplicação de diferentes fontes nitrogenadas na cultura da soja (Glycine Max L. Merrill), entre estes o rendimento de grãos, massa de mil grãos, relação de SPAD x fonte de N. O ensaio foi conduzido no ano agrícola de 2014, cultivar SYN 1059 VTOP, distribuídas em blocos casualizados, com quatro repetições e cinco tratamentos. A avaliação ocorreu em quatro estádios de desenvolvimento da planta. As leituras com clorofilômetro e a determinação dos teores de nitrogênio da folha foram realizadas nos estádios V5, R1, R3 e R 5.5. A utilização de N em cobertura proporcionou aumento no rendimento da soja, quando aplicado o produto Kimcoat $\mathrm{N}^{\circledR}$, tendo um resultado positivo quanto ao rendimento de grãos e viabilidade econômica de aplicação. A relação SPAD x teor de N, obteve correlação nos estádios V5 e R1 estádios onde foi determinado o rendimento (número de grãos) da cultura da soja, justificando sua aplicação.
\end{abstract}

Palavras-chave: Manejo de adubação. Análise foliar. Clorofilometria.

\begin{abstract}
It has been placed a special attention on the use of nitrogen fertilizer in soybeans culture in the past years in Brazil. The following experiment was realized at the Universidade do Oeste de Santa Catarina UNOESC, in Maravilha - SC, aiming to evaluate the Technical and economic efficiency of soybean culture under different nitrogen-containing sources (Glycine Max L. Merrill), among them, the grains yield, the thousand-grains mass and the SPAD versus Nitrogen source correlation. The essay was conducted in the 2014 agricultural year; the SYN 1059 VTOP cultivar was randomly scattered in blocks with four repetitions and five treatments. The evaluation was made in four stages of the plant development. The analysis with chlorophilometer and the determination of nitrogen levels in leave were realized during the stages V5, R1, R3 and R 5.5. The use of nitrogen in the covering has brought an increase of soybeans yield when the product Kimcoat $N ®$ was applied, showing a positive result - with regards to grains yield and economic feasibility. The analysis SPAD versus N level was achieved correlation in the stages V5 and R1, wherein the yield of soybeans culture (grains number) was defined, justifying thus its application.
\end{abstract}

Keywords - fertilizer management. leaf analysis. Chlorophyll. 


\section{INTRODUÇÃO}

O Brasil é o segundo maior produtor mundial de soja, fica atrás dos EUA. Na safra 2013/2014, a cultura ocupou uma área de 30,1 milhões de hectares, o que totalizou uma produção de 85,6 milhões de toneladas. A produtividade média da soja brasileira foi de $2.842 \mathrm{~kg}$ por hectare. (EMBRAPA, 2015).

As culturas de interesse agrícola necessitam do emprego de adubações para elevar a produtividade, sendo que a adubação nitrogenada é uma prática que assegura aumento de produtividade. No entanto, a soja, devido sua especificidade com bactérias do gênero bradirrizóbio consegue fixar a totalidade de $\mathrm{N}$ necessário para o pleno desenvolvimento e produção (HUNGRIA et al, 2007). Até o presente momento não há trabalhos que avaliem o aumento de produtividade, com adubos nitrogenados de liberação lenta e os teores de $\mathrm{N}$ no solo sob o cultivo de soja, principalmente em diferentes fontes de adubação nitrogenada.

O nitrogênio é um elemento que sofre diversas transformações até ser absorvido pelas plantas, sendo que durante estas transformações podem ocorrer perdas, principalmente de amônia. Além disso, existem perdas deste nutriente na forma de nitrato pela lixiviação e na forma gasosa através da desnitrificação (CANTARELA, 2007).

O manejo do nitrogênio tem sido uma das práticas agrícolas mais estudadas no sentido de melhorar a sua eficiência de uso (CANTARELA, 2007). Essa necessidade existe porque a maior parte do nitrogênio do solo se encontra em combinações orgânicas, sendo essa forma indisponível para os vegetais. Uma alternativa para fornecer o $\mathrm{N}$ para as plantas é através do uso de adubos nitrogenados, sendo a ureia $\left[\mathrm{CO}\left(\mathrm{NH}_{2}\right)_{2}\right]$, o fertilizante mais utilizado na agricultura (SOUSA; SILVA, 2009).

Para uma eficiente utilização de $\mathrm{N}$ pelas culturas, o elemento deve estar presente em formas inorgânicas $\mathrm{NH}_{4}{ }^{+}$ou $\mathrm{NO}_{3}{ }^{-}$para que seja absorvido pelas plantas (Souza \& Fernandes, 2006). Estas são as formas com que o $\mathrm{N}$ é liberado ao solo pelos adubos nitrogenados, sendo seu grau de liberação dependente do fertilizante nitrogenado utilizado.

$\mathrm{Na}$ agricultura, o nitrogênio requerido pelas culturas vem sendo suprida pelo fornecimento de fertilizantes químicos e pela fixação biológica. Quando a adubação nitrogenada é utilizada de forma inadequada, pode ocorrer um desequilíbrio de nutrientes essenciais às culturas, gerando aumento no custo de produção e podendo ainda acarretar o aparecimento de doenças nas plantas, além de efeitos ecológicos indesejáveis, tais como a eutrofização de águas superficiais e a contaminação de águas subterrâneas (Silva et al, 2010).

Grande parte do nitrogênio encontrado no solo está na forma orgânica, presente na matéria orgânica em diferentes moléculas ou como parte de organismos vivos. Entretanto, estes compostos nitrogenados são, em geral, rapidamente transformados em substâncias mais simples (NH4+ e NO3-) por organismos que vivem no solo (SILVA et al. 2010). As frações inorgânicas do nitrogênio são compostas principalmente por $\mathrm{NH}_{4}^{+}$e $\mathrm{NO}_{3}^{-}$, mas pequenas concentrações de NO2- podem ocorrer em algumas situações.

O teor de clorofila na folha é utilizado para predizer o nível nutricional de nitrogênio $(\mathrm{N})$ em plantas, devido ao fato de a quantidade desse pigmento correlacionar-se positivamente com teor de $\mathrm{N}$ na planta (BOOIJ et al., 2000). Por apresentar baixa sensibilidade ao consumo de luxo de $\mathrm{N}$, a medição efetuada pelo medidor de clorofila está sendo considerada melhor indicadora do nível desse nutriente na planta do que seu próprio teor (BLACKMER; SCHEPERS, 1995). As leituras efetuadas pelo medidor portátil de clorofila correspondem ao teor relativo de clorofila presente na folha da planta. Os valores são calculados pelo equipamento com base na quantidade de luz transmitida pela folha, em dois comprimentos de ondas, com diferentes absorbâncias da clorofila (Minolta, 1989).

O medidor de clorofila possui diodos que emitem luz a $650 \mathrm{~nm}$ (vermelho) e a $940 \mathrm{~nm}$ (infravermelho). A luz em $650 \mathrm{~nm}$ situa-se próxima dos dois comprimentos primários de ondas associados à atividade da clorofila (645 e $663 \mathrm{~nm})$. O comprimento de onda de $940 \mathrm{~nm}$ serve como referência interna para compensar diferenças na espessura ou no conteúdo de água da folha ou que sejam devidas a outros fatores (Waskom, 1996). A luz que passa através da amostra da folha atinge um receptor (fotodiodo de silicone) que converte a luz transmitida em sinais elétricos analógicos. Por meio do conversor A/D, esses sinais são amplificados e convertidos em sinais digitais (Minolta, 1989), sendo usados por um microprocessador para calcular os valores SPAD ("Soil plant analysis development"), que são mostrados num visor. Porém, existem poucos trabalhos que determinam a relação entre clorofila extraível e leitura do clorofilômetro em diferentes estádios de desenvolvimento da soja.

Os métodos tradicionais utilizados para determinar a quantidade de clorofila na folha requerem destruição de amostras de tecido e muito trabalho nos processos de extração e quantificação. $O$ recente 
desenvolvimento de um medidor portátil de clorofila, que permite medições instantâneas do valor correspondente ao seu teor na folha sem destruí-la, constitui uma alternativa para estimar o teor relativo desse pigmento na folha (ARGENTA et al., 2001).

Com este trabalho objetivou-se avaliar a eficiência econômica e técnica em relação as diferentes fontes nitrogenadas, e a relação entre a leitura do clorofilômetro com os teores de clorofila e de nitrogênio na folha em quatro estádios de desenvolvimento da soja.

\section{MATERIAL E MÉTODOS}

O experimento foi conduzido na área experimental da Universidade do Oeste de Santa Catarina - UNOESC, campus de Maravilha, situado no município de Maravilha, Santa Catarina, Brasil, representando as características do Oeste de Santa Catarina, situado nas coordenadas geográficas de $26^{\circ}$ $45^{\prime} 55^{\prime}$ ' S/ $53^{\circ} 11^{\prime} 43^{\prime \prime} \mathrm{W}$ e altitude de $574 \mathrm{~m}$. O clima é classificado como subtropical úmido, Cfa (Köppen). A precipitação ocorrida no período do trabalho foi de $1000 \mathrm{~mm}$. O solo é classificado como CAMBISSOLO Háplico (EMBRAPA, 2013), derivado de basalto, com relevo ondulado. As temperaturas médias anual, máxima e mínima são de $22,67^{\circ} \mathrm{C} ; 27,57^{\circ} \mathrm{C}, 17,76^{\circ} \mathrm{C}$, respectivamente.

A semeadura da cultura da soja foi realizada manualmente, no dia 20 de setembro de 2014, com espaçamento entre linhas de $0,50 \mathrm{~m}$ e população de plantas estabelecida de 380.000 plantas.ha ${ }^{-1}$. A colheita foi realizada no dia 23 de fevereiro de 2015. A cultivar de soja implantada no experimento foi SYN 1059 VTOP da Syngenta ${ }^{\circledR}$, que apresenta ciclo indeterminado. Esse cultivar é indicado para os plantios na região Sul período de setembro a novembro.

Os dados meteorológicos de precipitação pluviométrica e temperatura média diária (Gráfico 01) foi obtido junto a Empresa de Pesquisa Agropecuária e Extensão Rural de Santa Catarina/Centro de Pesquisa para a Agricultura Familiar (EPAGRI/CEPAF).

A análise de solo da área revelou os seguintes resultados: Argila 32\%; pH (água) 6,6; Índice SMP 6,7; 32,0 mg/dm ${ }^{3}$ de P; 236,0 mg/ $/ \mathrm{dm}^{3}$ de $\mathrm{K} ; 2,4 \%$ de M.O; 0,0 $\mathrm{cmol}_{\mathrm{c}} / \mathrm{dm}^{3}$ de Al; 9,9 $\mathrm{cmol}_{\mathrm{c}} / \mathrm{dm}^{3}$ de $\mathrm{Ca} ; 5,1$ $\mathrm{cmol}_{\mathrm{c}} / \mathrm{dm}^{3}$ de Mg; CTC (pH 7.0) de 17,64 $\mathrm{cmol}_{\mathrm{c}} / \mathrm{dm}^{3}$.

A aplicação de fósforo $(\mathrm{P})$, potássio $(\mathrm{K})$, foram calculadas segundo a Comissão de Química e Fertilidade do Solo / Rio Grande do Sul e Santa Catarina - CQFS (2004), sendo iguais para todas as parcelas. Com os resultados da análise química foi realizada a adubação, para estimativa de produção de $3000 \mathrm{~kg} / \mathrm{ha}$. Foram utilizados $45 \mathrm{Kg} /$ ha de $\mathrm{P}_{2} \mathrm{O}_{5}$, na semeadura e $70 \mathrm{~kg} /$ ha de $\mathrm{K}_{2} \mathrm{O}$.

Foi realizada adubação com nitrogênio na semeadura com 0,5 kg.ha- ${ }^{-1}$ na base e $45 \mathrm{~kg} \cdot \mathrm{N} \cdot \mathrm{ha}^{-1}$ cobertura, em duas aplicações estádio R3 (13/12/2014) e R5 (06/01/2015), dose esta definidas pelos autores do projeto, já que não há recomendação de adubação nitrogenada para a cultura da soja, conforme a CQFS (2004). A calagem não foi necessária ser realizada, conforme análise de solo.

A área experimental foi estabelecida em sistema de plantio direto, tendo como cultura antecessora aveia preta (Avena strigosa Schreb).

$\mathrm{O}$ experimento foi conduzido em delineamento de blocos casualizados (DBC). Cada tratamento com 04 repetições totalizando 24 unidades experimentais. Cada parcela com área de $2,712 \mathrm{~m}^{2}(1,13$ de largura $\mathrm{x} 2,40 \mathrm{~m}$ de comprimento) totalizando $10,848 \mathrm{~m}^{2}$ cada tratamento. A área total do experimento de $65,088 \mathrm{~m}^{2}$.

Realizou-se os tratamentos nos estádios R3 e R5: T1: Dura Max ${ }^{\circledR} 100 \mathrm{~kg} / \mathrm{ha}$, em duas aplicações, fórmula 45-00-00; T2: Cooper $\mathrm{N}^{\circledR} 100 \mathrm{~kg} / \mathrm{ha}$, em duas aplicações, fórmula 45-00-00; T3: Kimcoat ${ }^{\circledR}$ N 100 $\mathrm{kg} / \mathrm{ha}$, em duas aplicações, fórmula 45-00-00; T4: Sulfammo ${ }^{\circledR} 155,17 \mathrm{~kg} / \mathrm{ha}$, em duas aplicações, fórmula 29-00-00; T5: Nitromag ${ }^{\circledR}$ 166,67 $100 \mathrm{~kg} / \mathrm{ha}$, em duas aplicações, fórmula 27-00-00; T6: Nenhuma aplicação.

Após a emergência da soja, esta foi submetida a tratos culturais para controle de plantas infestantes. As sementes foram tratadas com 150 mL.ha ${ }^{-1}$ de inseticida de Cruiser $^{\circledR}$ ingrediente ativo Thiamethoxam

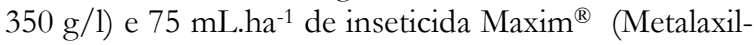
m 20 g/l e Fludioxonil 25 g/1 ). A dessecação da cultura antecessora foi realizada 20 dias antes da semeadura da cultura da soja, na dosagem de 1,5 L.ha-1 de Glufosinato de amônio. O controle das plantas daninhas foi realizado no estádio vegetativo V2, com uma aplicação de Glufosinato de amônio, na dose de 2,0 L.ha-1.

O controle das pragas e moléstias ocorreu nos estádios V2, V7, R2, R4 e R5.5. Com cinco aplicações.

Foi realizada a inoculação via semeadura, utilizando o inoculante líquido (Rhizomax ${ }^{\circledR}$ ), com as estirpes de Bradyrhizobium. japonicum SEMIA 5079 e 5080, na concentração bacteriana de 2,0 x 109 cels mL1. A dose recomendada deste inoculante é a aplicação de $100 \mathrm{ml}$ para cada $50 \mathrm{~kg}$ sementes.

As determinações realizadas: leitura correspondente ao teor de clorofila na folha com o clorofilômetro marca Minolta (modelo SPAD-502) e 
teores de clorofila extraível e de $\mathrm{N}$ total na folha. As determinações foram realizadas nos estádios V5, R1, R3 e R5.5. A leitura no medidor de clorofila foi feita em pontos situados na metade a dois terços do comprimento da folha amostrada, a partir da base, e a 2 $\mathrm{cm}$ de uma das margens da folha. Em folha trifoliada, folha do meio. Após a leitura, as folhas foram arrancadas para determinação dos teores de N. De cada folha (quatro por parcela), onde efetuou-se as leituras com o clorofilômetro. $\mathrm{O}$ teor de $\mathrm{N}$ foi determinado de acordo com metodologia descrita em Tedesco et al. (1995).

Após a colheita, os grãos foram limpos e pesados, e após determinado o teor de umidade. O rendimento de grãos (RG) foi estimado em $\mathrm{kg} \mathrm{ha}^{-1}$ a partir do peso de grãos de cada parcela $\left(1 \mathrm{~m}^{2}\right)$, realizouse a pesagem em balança de precisão dos grãos das plantas avaliadas em cada tratamento e, posteriormente, o valor foi extrapolado para hectare e corrigido para $14 \%$ de umidade. Onde: $\mathrm{O}$ valor de $\mathrm{f}$, multiplicado pelo peso obtido dos grãos, resultou na correção da umidade desejada. De posse dos dados (g.parcela-1), foi efetuado os cálculos para estimar o rendimento Sc.ha-1. A massa de mil grãos (MMG) foi avaliada por meio da pesagem de 1000 grãos escolhidos ao acaso, os valores foram corrigidos para umidade de $14 \%$.

Os dados coletados foram submetidos à análise de variância pelo teste F, pelo software SISVAR e as diferenças entre médias comparadas pelo teste Tukey a 0,05 de significância.

\section{RESULTADOS E DISCUSSÕES}

Durante o período de realização do experimento, ocorreram precipitações de $1.008,7 \mathrm{~mm}$, perante o exposto acima, corresponde a uma precipitação acima dos padrões ideais durante todo ciclo da cultura da soja (Figura 1). De acordo com Embrapa (2015a) para obtenção do rendimento máximo, a necessidade de água na cultura da soja, durante todo seu ciclo, varia entre 450 a $800 \mathrm{~mm}$, dependendo das condições climáticas, do manejo da cultura e da duração de seu ciclo.

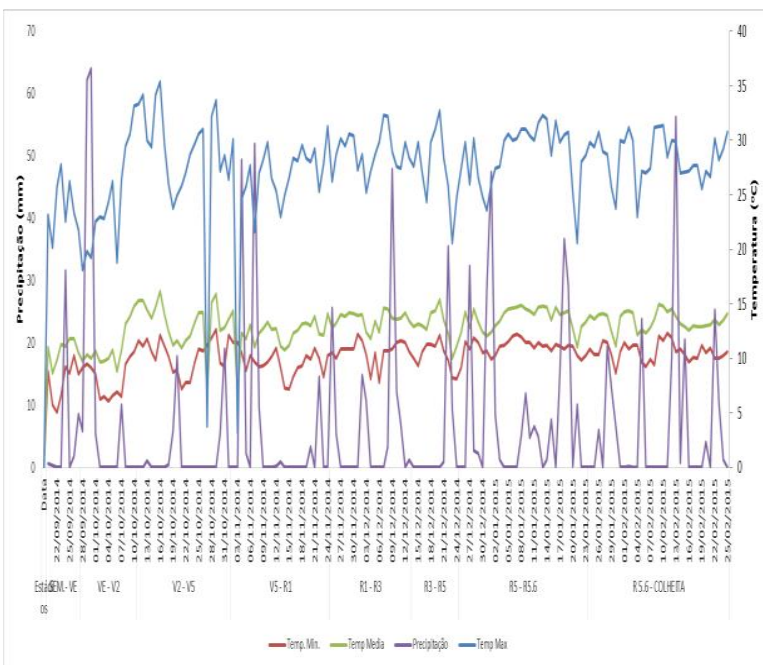

Figura 1: Dados meteorológicos da precipitação e temperatura. Fonte: Cepaf/Epagri (2015).

Figure 1: Meteorological precipitation and temperature data.

Nas condições deste experimento, a adubação nitrogenada em cobertura em soja apresentou resposta significativa sobre a produtividade e viabilidade econômica do produto Kimcoat $\mathrm{N}^{\circledR}$, resultou em um aumento de 11,43 sacas por hectare com um rendimento econômico de $\mathrm{R}$ \$ 469,98 (Tabela 1).

Conforme Cantarella (2007), após a adubação nitrogenada é importante à ocorrência de chuvas para incorporação dos fertilizantes e diminuição suas perdas, porém altos níveis de chuvas podem proporcionar perdas de $\mathrm{N}$ por lixiviação, considerando que em regiões mais frias as perdas por volatilização são menos significativas, uma vez que as mesmas são consideráveis perante ocorrência de umidade e altas temperaturas. Observa-se que após a aplicação via cobertura nos estádios R3 e R5 ocorreram as precipitação acima da exigência da cultura (Figura 1).

Os aditivos presentes no Kimcoat $\mathrm{N}^{\circledR}$ protegem o fertilizante nitrogenado (ureia) das principais perdas que ocorrem no processo de adubação, como: volatilização de $\mathrm{NH}_{3}$, nitrificação e desnitrificação e permitem uma disponibilização de nutriente mais progressiva, ajustada à demanda das plantas durante o seu ciclo. O processo de perda por volatilização consiste na passagem da amônia $\left(\mathrm{NH}_{3}\right)$ presente no solo à atmosfera, podendo chegar a $80 \%$ em situações mais extremas. O Kimcoat $\mathrm{N}^{\circledR}$ é formulado com ingredientes solúveis e biodegradáveis, que são amigáveis com o meio ambiente, pois permitem o uso racional de insumos em sistemas intensivos de produção. $O$ revestimento tem ação 
química e física nesse processo: quimicamente atua retardando a atividade da enzima uréase (menor volatilização de amônia $\mathrm{NH}_{3}$ ) e diminuindo a ação de nitrificação no solo, mantendo o $\mathrm{N}$ em sua maior parte na forma de amônio, consequentemente gerando menor gasto de ATP pela planta nos processos assimilatórios de nutrientes. Fisicamente o revestimento interfere no processo de liberação de nutrientes, disponibilizando os nutrientes de forma mais lenta e contínua para solução do solo. (KIMBERLIT, 2015).

Segundo RIQUETTTI (2012) a enzima uréase é responsável pela hidrólise da ureia, essa enzima é comum na natureza e está presente em microrganismos, plantas e animais. O inibidor de uréase permite maior tempo para que o fertilizante seja incorporado ao solo pela precipitação pluvial sem que ocorram perdas significativas de nitrogênio. Além da fonte de nitrogênio utilizada, as condições meteorológicas, principalmente a disponibilidade hídrica, e o manejo da adubação nitrogenada influenciam na eficiência de uso do $\mathrm{N}$ aplicado. A precipitação pode aumentar as perdas de $\mathrm{N}$, pois a adição de água ao solo permite que ocorra a dissolução da ureia e início da hidrólise. Porém, a chuva tem o potencial para transporte de ureia e $\mathrm{N}$ amoniacal em profundidade no solo, aumentando a adsorção e reduzindo a perda por volatilização. Conforme Cantarella (2007), é necessária precipitação de 10 a 20 $\mathrm{mm}$, para que a ureia seja incorporada ao solo após a sua aplicação.

As perdas de $\mathrm{N}$ podem ser reduzidas através de práticas que forneçam $\mathrm{N}$ de forma mais eficiente para as culturas. Tais práticas que melhoram o uso da $\mathrm{N}$ incluem o uso de fertilizantes de liberação lenta ou controlados por inibidores da nitrificação, que retardam os processos microbianos de liberação e formação de $\mathrm{N}_{2} \mathrm{O}$ (SNYDER et al., 2009).

Os Inibidores da nitrificação têm o potencial para reduzir a perda de $\mathrm{N}$ solos e aumentar a eficiência uso do $\mathrm{N}$ pelas plantas, como o próprio nome sugere o produto trabalham para inibir a transformação de $\mathrm{N}$ através da via de nitrificação que resulta na retenção de mais prolongada de $\mathrm{N}^{-\mathrm{NH}_{4}}{ }^{+}$nos solos (SIMON, 2015).

Na correlações de Pearson (Rxy) nos estádios V5 e R1 na cultura da soja submetida fonte nitrogenada Kimcoat $\mathrm{N}^{\circledR}$ (Tabela 2), evidenciando a eficiência do referido produto no final do estádio V5 e início do estádio R1 (estádio fundamental para a definição de um dos principais componentes de rendimento da cultura da soja: número de flores por área).
O custo para realização da aplicação foi feito considerando as horas necessárias para esse procedimento, sendo que o valor estimado em $\mathrm{R} \$ 100,00 /$ hora e também o custo dos nitrogenados foi divido por quilograma e por hectare e depois calculado para chegar nos $45 \mathrm{~kg}$ de $\mathrm{N}$ por hectare.

Com um rendimento de $685.8 \mathrm{~kg} / \mathrm{ha}$ ou 11,43 sacas com um preço médio de $\mathrm{R} \$ 60,00$ por saca, se equivale a $\mathrm{R} \$ 685,80$ a mais que a testemunha, sendo que o custo para a aplicação do Kimcoat $\mathrm{N}^{\circledR}$ teve um custo de R\$215,67 que teria uma margem líquida de $\mathrm{R} \$ 469,98$ e torna a prática de aplicação de $\mathrm{N}$ em cobertura economicamente viável (Tabela 3).

Considera-se que a busca por qualificação juntamente com as informações técnicas melhora a eficiência na produção da soja, tornando-se, de certo modo, economicamente viável para o empreendedor rural. Ainda, a prática de aplicação de $\mathrm{N}$ em cobertura é considerada uma técnica rentável em alguns casos para o cultivo da soja, uma vez que esse método apresentou vantagens em dois produtos assim proporcionando ganhos econômicos significativos quanto ao seu uso.

Essas informações mostram ao produtor o custo da aplicação por ha e a viabilidade da aplicação de $\mathrm{N}$ em cobertura na cultura da soja que o auxilia no planejamento das ações futuras. Pois com o planejamento e controle do custo de produção, pode-se obter retornos financeiros.

\section{CONCLUSÕES}

A utilização de $\mathrm{N}$ em cobertura proporcionou aumento no rendimento da soja, quando aplicado o produto Kimcoat $\mathrm{N}^{\circledR}$, tendo um resultado positivo quanto ao rendimento de grãos e viabilidade econômica de aplicação.

A relação SPAD $\mathrm{x}$ teor de $\mathrm{N}$, obteve correlação nos estádios V5 e R1 estádios onde definimos o rendimento (número de grãos) da cultura da soja, justificando sua aplicação. 
Tabela 1. Análise de rendimento, número de vagens e peso de 1000 grãos relacionado a aplicação de nitrogênio em cobertura na cultura da soja (Glycine Max $L$. Merrill).

Table 1. performance analysis, number of pods and weight of 1000 grains related to nitrogen application coverage in soybean (Glycine Max L. Merrill).

\begin{tabular}{|c|c|c|c|}
\hline Tratamentos & Rendimento & $\mathrm{N}^{\circ}$ de vagens & Peso 1000 \\
\hline Dura $\max \AA$ & $5175.77 \mathrm{~b}$ & $118,50 \mathrm{a}$ & $213,00 \quad b$ \\
\hline Cooper $N \mathbb{R}$ & $4972.67 \mathrm{~b}$ & $123,25 \mathrm{a}$ & $208,75 \quad b$ \\
\hline Kimcoat $N ®$ & $5377.15 \mathrm{a}$ & $115,25 \mathrm{a}$ & $219,00 \quad a b$ \\
\hline Sulfammo® & $4906.00 \mathrm{~b}$ & $106,00 \mathrm{a}$ & $221,75 \mathrm{ab}$ \\
\hline Nitromag $\mathbb{R}$ & $4720.57 \mathrm{~b}$ & $101,75 \mathrm{a}$ & 239,75 \\
\hline \multirow[t]{2}{*}{ Testemunha } & $4897.20 \mathrm{~b}$ & $114,25 \mathrm{a}$ & $224,25 \mathrm{ab}$ \\
\hline & $\mathrm{CV}(\%)=10$ & $\mathrm{CV}(\%)=22,39$ & $\mathrm{CV}(\%)=3,12$ \\
\hline
\end{tabular}

Médias seguidas pela mesma letra, dentro da mesma coluna, não diferem estatisticamente ao nível de $5 \%$ de probabilidade pelo teste de Tukey; Valores de CV indica o coeficiente de variação (\%).

Tabela 2. Relação leitura SPAD e teor de $\mathrm{N}$ na folha em soja submetida a fontes nitrogenadas em diferentes estádios ontogênicos. Maravilha/SC, 2015.

Table 2. Reading relationship SPAD and N content in soybean leaf subjected to nitrogen sources at different ontogenetic stages.

\begin{tabular}{|c|c|c|c|c|}
\hline Estádio & Fontes N & SPAD & Teor de N & Correlação \\
\hline \multirow{6}{*}{ V5 } & Dura max $®$ & 39,71875 & 5,270625 & $-0,021081343$ ns \\
\hline & Cooper $\mathrm{N} \circledast$ & 38,025 & 5,29375 & $-0,539451715^{\mathrm{ns}}$ \\
\hline & Kimcoat $N \circledR$ & 36,425 & 5,075 & $0,938075381 *$ \\
\hline & Sulfammo ${ }^{\circledR}$ & 41,775 & 5,81875 & 0,324971744 ns \\
\hline & Nitromag ( & 37,25625 & 5,075 & $-0,621690682 \mathrm{~ns}$ \\
\hline & Testemunha & 37,8475 & 4,76875 & $-0,280216296 \mathrm{~ns}$ \\
\hline \multirow{6}{*}{$\mathrm{R} 1$} & 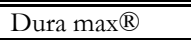 & 40,6563 & $4,4,9000$ & $0,0,345120891$ ns \\
\hline & Cooper $\mathrm{N} \circledast$ & 39,2688 & 4,9000 & $0,739075798 *$ \\
\hline & Kimcoat $N ®$ & 30,0563 & 4,6375 & $-0,762420575 *$ \\
\hline & Sulfammo® & 38,7688 & 4,9438 & 0,254949533 ns \\
\hline & Nitromag® & 38,7250 & 5,0313 & 0,377636166 ns \\
\hline & \begin{tabular}{|l|} 
Testemunha \\
\end{tabular} & 30,6875 & 4,5938 & $-0,54350564 \mathrm{~ns}$ \\
\hline \multirow{6}{*}{$\mathrm{R} 3$} & D Dura max ${ }^{\circledR}$ & 42,91875 & 4,66375 & $-0,026661927 \mathrm{~ns}$ \\
\hline & Cooper $\mathrm{N} \AA$ & 46,1125 & 5,186875 & $-0,144434216 \mathrm{~ns}$ \\
\hline & Kimcoat $\mathrm{N} \AA$ & 46,4875 & 4,97 & $-0,552015953 \mathrm{~ns}$ \\
\hline & 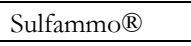 & 46,93125 & 5,97625 & $-0,099710511 \mathrm{~ns}$ \\
\hline & Nitromag® & 46,01875 & 5,5825 & $0,115441167^{\mathrm{ns}}$ \\
\hline & Testemunha & 46,09375 & 5,45125 & $-0,155434675^{\mathrm{ns}}$ \\
\hline \multirow{6}{*}{ R5.6 } & Dura max $®$ & 50,33125 & $-4,2875$ & 0,088226758 ns \\
\hline & Cooper $\mathrm{N} 囚$ & 48,70625 & 4,24375 & 0,586696138 ns \\
\hline & Kimcoat $\mathrm{N}{ }^{\circledR}$ & 52,75625 & 4,59375 & 0,413498025 ns \\
\hline & Sulfammo $\mathbb{}$ & 51,4125 & 3,98125 & $-0,054944513$ ns \\
\hline & Nitromag@ & 51,19375 & 4,50625 & $-0,680985673 \mathrm{~ns}$ \\
\hline & Testemunha & 51,19375 & 4,41875 & 0,080845208 ns \\
\hline
\end{tabular}

Legenda: ${ }^{\text {ns }}$ não significativo a $5 \%$ probabilidade. * significativo a $5 \%$ probabilidade.

Tabela 3. Custo e margem líquida da aplicação de nitrogênio por hectare.

Table 3. Cost and net margin per hectare nitrogen application.

\begin{tabular}{|c|c|c|c|c|c|c|c|c|c|}
\hline Tratamentos & $\begin{array}{c}\text { Custo hora } \\
\text { /máquina } \\
\text { R\$ }\end{array}$ & $\begin{array}{c}\text { Custo } \\
\text { por Kg } \\
\text { R\$ }\end{array}$ & $\begin{array}{c}\text { Quantidade } \\
\text { KG/ha }\end{array}$ & $\begin{array}{l}\text { Valor do } \\
\text { N/ha R\$ }\end{array}$ & $\begin{array}{l}\text { Custo } \\
\text { Total }\end{array}$ & $\begin{array}{c}\text { Diferença } \\
\text { em Sc }\end{array}$ & $\begin{array}{c}\text { Preço } \\
\text { saca }\end{array}$ & $\begin{array}{l}\text { Lucro } \\
\text { bruto }\end{array}$ & $\begin{array}{l}\text { Lucro } \\
\text { líquido }\end{array}$ \\
\hline 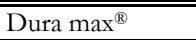 & (266,67 & 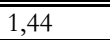 & 10100,00 & $1 \overline{144,00}$ & 210,67 & 6,63 & 60,00 & 397,95 & 187,28 \\
\hline Cooper $\mathrm{N}^{\circledR}$ & 66,67 & 1,47 & 100,00 & 147,00 & 213,67 & 1,80 & 60,00 & 107,80 & $-105,87$ \\
\hline Kimcoat $\mathrm{N}^{\circledR}$ & 66,67 & 1,49 & 100,00 & 149,00 & 215,67 & 11,43 & 60,00 & 685,65 & 469,98 \\
\hline Sulfammo ${ }^{\circledR}$ & 66,67 & 1,75 & 155,17 & 271,55 & 338,22 & 0,21 & 60,00 & 12,60 & $-325,62$ \\
\hline Nitromag $^{\sqrt{ }}$ & 66,67 & 1,16 & 166,67 & 193,34 & 260,01 & $-4,21$ & 60,00 & $-252,30$ & $-512,31$ \\
\hline Testemunha & - & - & - & - & - & - & - & - & - \\
\hline
\end{tabular}




\section{REFERÊNCIAS}

ARGENTA, G. Monitoramento do nivel de nitrogênio na planta como indicador da adubação nitrogenada em milho. Tese de Doutorado. Porto Alegre, Universidade Federal do Rio Grande do Sul, 2001. 112p.

BLACKMER, T.M. e SCHEPERS, J.S. Use of chorophyll meter to monitor nitrogen status and schedule fertigation for corn. Journal of Production Agriculture, 8:56-60, 1995.

BOOIJ, R.; VALENZUELA, J.L. e AGUILERA, C. Determination of crop nitrogen status using non-invasive methods. In: HAVERKORT, A.J.; MACKERRON, D.K.L. (Eds.). Management of nitrogen and water in potato production. The Netherlands, Wageningen Pers, 2000. p.72-82.

CANTARELA, H. Nitrogênio. In: Fertilidade do Solo. NOVAIS, R. F. ALVAREZ, V. H. BARROS, N. F. FONTES, R. L. F. CANTARUTTI, R. B. NEVES, J. L. Sociedade Brasileira de Ciências do Solo. Viçosa, MG. 1 ed. 2007. 1017P.

COMISSÃO DE QUÍMICA E FERTILIDADE - RS/SC. Manual de adubação e calagem para os Estados de Rio Grande do Sul e Santa Catarina. Sociedade Brasileira de Ciências do Solo. 10 ed. Porto Alegre. 2004. 400p.

EMBRAPA. Centro nacional de pesquisa de solos. Sistema Brasileiro de Classificação do Solo. ed 2 ${ }^{\circ}$, Rio de Janeiro-RJ. 2013. 306p.

EMBRAPA. Soja. Disponível em: https://www.embrapa.br/soja/cultivos/soja Acesso em 10 de abril.2015.

EMBRAPA. Exigências climáticas. Disponível em: http://sistemasdeproducao.cnptia.embrapa.br/FontesHTML /Soja/CultivodeSojanoCerradodeRoraima/clima.htm Acesso em 10 de abril. 2015a.

HUNGRIA, M.; CAMPO, R. J.; MENDES, I. C. A importância do processo de fixação biologica do nitrogênio para a cultura da soja: componente essencial para a competitividade do produto brasileiro. Londrina: Embrapa Soja, 2007.

KIMBERTLIT $^{\circledR}$ Adubo Kimcoat $N$ [mensagem pessoal]. Mensagem recebida por: alexandres@,cooperauriverde.com.br em 05 de maio 2015.
MINOLTA, C. C. Ltda. Manual for chlorophyll meter SPAD 502. Osaka, Minolta, Radiometric Instruments divisions. 1989. 22p.

RIQUETTI, C. DA SILVA, P. R. F. MENEGATI, G. B. CORREIA, S. D. L. SERPA M. D. S. MENEZES, G. B. CAMARGO, D. LOPES, F. Eficiência do Uso da Ureia com Inibidor da Enzima Urease em Milho. XXIX CONGRESSO NACIONAL DE MILHO E SORGO - Águas de Lindóia RS. 26 a 30 de Agosto de 2012

SILVA, D. DE F.; ANDRADE, C. D. L. T. DE.; SIMEONE, M. L. F.; AMARAL, T. A.; DE CASTRO, L. A.; MOURA, B. F. Análise de Nitrato e Amônio em Solo e Água. Embrapa Milho e Sorgo Sete Lagoas, MG, 2010. (Documentos / Embrapa Milho e Sorgo, ISSN 1518 - 4277; 114).

SNYDER, C.S.; BRUULSEMA, T.W. JENSEN, T.L.; FIXEN, P.E. Review of greenhouse gas emissions from crop production systems and fertilizer management effects. Agriculture, Ecosystems and Environment, 133, 247-266, 2009.

SIMON, P. Emissões Diretas de Óxido Nitroso de Dejetos Bovinos em Pastagem e Mitigação por Dicianodiamida (DCD). Dissertação apresentada ao Programa de Pós Graduação em Ciência do Solo. Universidade Federal do Paraná. Curitiba/PR. 2015. 44P.

SOUSA, R. A.; SILVA, T. R. B. Typic Hapludox acidification with the application of nitrogen arising from urea, ammonium sulfate and sulfammo. Cultivando o Saber, Cascavel, v.2, n.3, p.78-83, 2009.

SOUZA, R. S.; FERNANDES, M. S. Nitrogênio. In: FERNANDES. M. S. Nutrição mineral de plantas. Sociedade Brasileira de Ciência do Solo, 2006. Viçosa, MG.

TEDESCO, M. J.; GIANELLO, C.; BISSANI C. A.; BOHNEN, H.; VOLKWEISS, S. J. Análise de solo, Plantas e Outros Materiais. Porto Alegre: UFRGS, 1995.

WASKOM, R.M., WESTFALL, D.G., SPELLMAN, D.E., et al. Monitoring nitrogen status of corn with a portable chlorophyll meter. Communications in Soil Science and Plant Analysis, New York, v.27, n.3, p.545-560, 1996. 